\title{
Neues Maximalthermoneter.
}

Bisweilen lat man nicht unerhebliche Schwierigkeiten, bei einem Maximalthermometer den Quecksilberfaden wieder in das Quecksilbergefäl3 zurückzutreiben, und manches Thermometer ist schon dem Aufwand ron Kraft, welchen namentlich nicht ganz geschickte Laien bei dieser Prozedur oft beweisen, zum Opfer gefallen. Man kann dalıer den Versuch, den die Firma Grösche \& Koch (llmenau) zur Ablilfe dieses Uebelstandes mit der Konstruktion ibrer „Patenthïlse“ gernacht hat, gern anerlkennen. Die Maximalthermometer haben bekanntlich im Quecksilbergefäß einen festgeschmolzenen Stift aus Glas, welcher in den nnteren Teil der

Fig. 1.

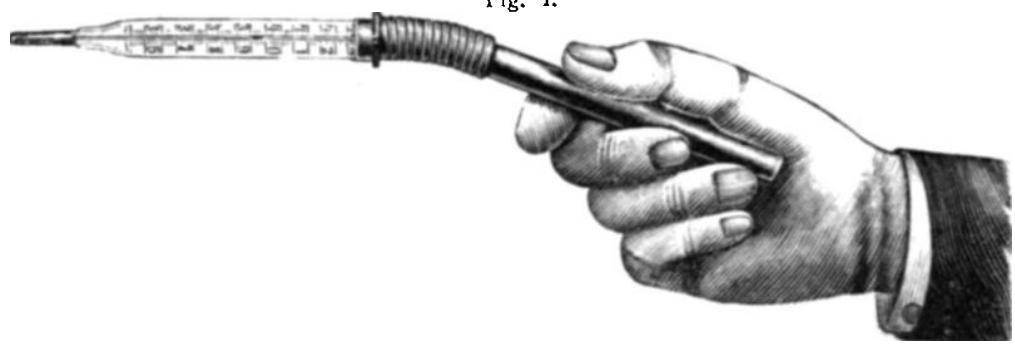

Thermometer im Gebrauch,

Fig. 2.

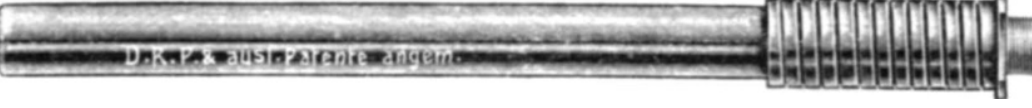

in der Hülse.

Capillare hineinreicht. Dieser Stift ist die Ursache, daß3 der die Temperatır anzeigende Quecksilberfaden in der Capillare stehen bleibt und auch dann nicht von selbst in das Quecksilbergefä $B$ sich zurückzieht, wenn das Thermometer von der Wärmeqnelle entfernt wird. Tim nun den Quecksilberfaden zurückzutreiben, wird Grösches Patenthülse als Verlängerung an die Kopfschranbe des Thermometers fest angeschraubt, die Hiilse am Ende erfaßt, und dann werden ruckweise einige Schläge damit ausgefiihrt. Eine elastische Feder der Patenthillse setzt die Schläge in vielfache Vibrationen um and bewirkt, wie ich mich mehrfach ïberzougt habe, ein überraschend leichtes Zurúckgehen des Quecksilberfadens. Das Thermometer kostet etwa $2,50-3,00 \mathrm{M}$.

J. Scliwalbe. 